\title{
An Evaluation of High School Curricula Employing Using the Element-based Curriculum Development Model
}

\author{
Dolgun Aslan ${ }^{1}$, Rafet Günay ${ }^{2}$ \\ ${ }^{1}$ Ministry of National Education, Istanbul, Turkey \\ ${ }^{2}$ School of Education, Curriculum and Instruction, Yildiz Technical University, Istanbul, Turkey. \\ Correspondence: Dolgun Aslan, Ministry of National Education, Istanbul, Turkey
}

Received: March 22, 2016 Accepted: April 7, $2016 \quad$ Online Published: April 14, 2016

doi:10.11114/jets.v4i7.1477 URL: http://dx.doi.org/10.11114/jets.v4i7.1477

\begin{abstract}
This study was conducted with the aim of evaluating the curricula that constitute the basis of education provision at high schools in Turkey from the perspective of the teachers involved. A descriptive survey model, a quantitative research method was employed in this study. An item-based curriculum evaluation model was employed as part of the evaluation process. The data for the study were obtained from the 199 participant teachers via an "evaluation questionnaire of the high school curriculum. This questionnaire was designed after careful consideration of the key elements of the curriculum. The evaluations submitted by teachers with regard to the items contained within the survey were carefully interpreted. This followed the clear identification of the percentages, frequencies and averages involved. According to the findings obtained from the study, the opinions of teachers concerning the components of the High School Teaching Program when taken as a whole were found to be at an average level. As concerns all elements of the program, teachers were found to most closely agree with those statements within the "(I) partly disagree"category. Results indicated a higher percentage of responses that corresponded with the "definitely disagree" or "disagree" categories than for the "definitely agree" or "agree" categories.
\end{abstract}

Keywords: curriculum evaluation, element-based evaluation, High School (teaching) curriculum, opinions of teachers

\section{Introduction}

In order to address certain requirements of the school system and to utilize available opportunities so as to work towards reaching assigned objectives in a way that is both effective in manner and productive in outcome., it is necessary to monitor established practices at clear intervals. Only through feedback from users of the system and an identification of issues that arise, it is possible to reduce the numbers of shortcomings and inadequacies of such a system. Only through detailed feedback can practices that serve goal-orientated systems be lent transparency. When trying to enact change in a system and by doing so to ultimatelyy create a system that is open to development, it is essential to outline and incorporate both those activities that are to be applied as part of the system as well as to include (well-defined) activities that offer opportunities for evaluation. Demirel (2013) emphasises that the school curriculum is able to respond to the needs that are placed upon it and ultimately achieve its ultimate objectives only through the initial clear articulation of the program's objectives, content, and the teaching-learning process in terms of a series of dynamic relations on a clearly-defined scale of evaluation. Varış (1976) defines curriculum development as the coordination of efforts to develop appropriate methods and techniques with the purpose of achieving the goals defined by the national educational system and the school itself.

Erden (1998) defines curriculum evaluation as a process of reaching results. This process of evaluation consists of first acquiring data concerning the effectiveness of teaching programs at the application stage through the use of various means of measurement. A comparison of the types of data obtained should then be conducted employing clearly defined criteria, followed by a stage of evaluation and interpretation. This comparison of data serves to raise the level of effectiveness of the program. Ornstein and Hunkins (2009) define evaluation as all activities relating to the acquisition of scientific results that allow the opportunity for individuals to make decisions on issues concerning whether or not curricula (in current practice) are to be accepted, changed or completely abandoned.

Ertürk (1992), for his part, qualifies evaluation as a final, yet self-standing element of the curriculum. Koufman and Thomas (1980) see evaluation as a process which allows for the carrying out of necessary changes in light of feedback 
obtained from its users. This feedback should emphasize the problems experienced through application of the program and indicate from which elements of the curriculum existing problems originate. This allows for the identification of deficiencies and faults in the existing system and for decisions to be made regarding the overall effectiveness of the curriculum in reaching its ultimate objectives. Erden (1998) emphasizes that curricula are in a state of constant development as a result of insights obtained as a result of research into the transformations and changes across a number of social and scientific academic fields. The reduction of the deficiencies and shortcomings in curricula currently in practice can only lead to an increase in the quality of education delivered. In this regard, it may be argued that whether from an individual or societal perspective, true acquisition of knowledge and skills is only possible through the adoption of a philosophy of curriculum development based on curriculum evaluation. Curriculum development can only be realized through the careful consideration of feedback obtained from its users (Aydin, 2012). Tyler (2013) emphasized that curriculum evaluation ought indeed to indicate the rate at which the pre-defined educational objectives set out have been reached. Howeveri it also needs to incorporate a process in which research is conducted that helps to explain why certain set targets are not successfully attained and to devise strategies aimed at eradication of the deficiencies and faults in the system.

Significant changes and developments across a number of fields have taken place within the context of wide societal and economic transformations and reforms at a global level. Turkey is in need of fundamental and far- reaching reform with regard to curriculum development so as to address the effects of these changes and to foster quality human capital by means of its educational system, (Aslan \& Aydin, 2015). In the above context, reforms have been enacted in Turkey with regard to fostering appropriate economic, social and cultural values (Yurtseven \& Altun, 2015) The contemporary field of curriculum development takes as its guiding principle the set of (progressive) values that are spread and interwoven in our contemporary world (Aydin, 2013; Karatas \& Oral, 2015; Kaya, 2015). (Demirel, 2013). As a consquence of these changes in outlook with regard to the values to be contained in school programs, the high school teaching curricula that form the focus of this research were accepted and taken to be the cornerstone of education at high schools (MEGEP, 2006). The acceptance of the new high school curricula came after the introduction of the new primary school law in 2005-2006, In place of topic and teacher-centred approaches, attention was focused on student and process-centred approaches that placed importance on constructivist teaching theory. As a result, there was a transition from a sitution in which students were seen as mere passive recipients of knowledge within the teaching and learning processes to a revised system in which importance was instead placed on inclusion of students within a process of active participation. In such a new system, students were to learn through experience and the carrying out of tasks. This revised approach would allow them to transform theoretical attainment objectives into applicable outcomes. If the elements of the new curricula are examined, it may be observed that in the setting out of attainment objectives, more attention is paid to the qualities and attributes of the students. Educators embark therefore on a path that attaches importance to the multi-dimensional development of the students concerned. In the definition of the content components/elements, importance is placed in particular on the knowledge and skills required in daily life and the abilities to carry out these at a functional level. With regard to the components of the curriculum regarding the educational situations, more importance is given to the participation of the student, and in particular to the value of participation over theoretical knowledge. At the evaluation stage, performance and process-based evaluations are regarded as vital (Sönmez, 2015).

Yüksel and Sağlam (2012) demonstrate that within the curriculum evaluation process, the behaviors/attitudes of those responsible for assessment and evaluation at the initial evaluation level reflect a great variation according to the educational theories and philosophies to which they attach importance. With regard to the basic components that are to be taken as the fundemental units of evaluation, they stated that five different forms of evaluation may be observed: the objective or target-based, the administration-based, the expert-based, the consumer-based and the participant based models.

The evaluation model that forms the basis of this study is the "Element-Based Curriculum Evaluation Model" developed by Erden. According to the Element Based Evaluation Model, the opinions/viewpoints of participants regarding all components of the program are to be taken into consideration (Hakan, Sağlam, Sever ve Vural, 2011). The Element-Based Curriculum Evaluation Model is preferred on account of the manner in that it may provide information on issues such as whether objectives are such that they may be realized within a particular set process of application, whether the targets are compatible with the reliability principle, whether the program allows the opportunity for the provision of educational contexts or conditions that permit the implementation of content and the realization of presecribed objectives and whether the programs have reached the prescribed objectives. In such a way, the element-based curriculum evaluation model was considered from the perspective of its ability to allow for activities that could form the basis of the educational context stage and permit the researchers the opportunity to identify as to whether 
or not targets had been met at the evaluation stage of the program as well as to cater for a more comprehensive hollistic evaluation of the system.

According to Erden (1998), at the program evaluation stage, answers are/should be sought to the following questions/researchers are to seek answers to the following questions:

a. To what extent are the targets set out in the curriculum realized?

b. What are the basic deficiencies and problems of the curriculum?

It follows that the first question indicated in item a. "is to be considered more in the context of "evaluation through consideration of the output and the outcome of the curriculum" and item b. "within the context of curriculum element-based assessment".

The evaluation of the output and the outcome, while providing us with information concerning the effect level at target point, is unable to provide the opportunity to gain feedback regarding other elements of the curriculum. In this regard, in order to see and address all deficiencies and inadequacies concerning the other elements (targets, content, education contexts and evaluation) of the program, there is a need to implement curriculum-element based evalution. The hollistic evaluation of a curriculum is only possible through the acquisition of data regarding all elements included within the program (Bayrak \& Erden, 2007). In this study, the principal reason for employing the Element-Based Curriculum Evaluation Model developed by Erden is that it allows for hollistic evaluation that considers all elements of the program. Erden indicated that the questions concerning the elements of the curriculum should be formulated so as to conduct an evaluation that took into consideration all components of the "element-based evaluation model" and employed a hollistic approach, as follows.

Table 1. Curriculum items

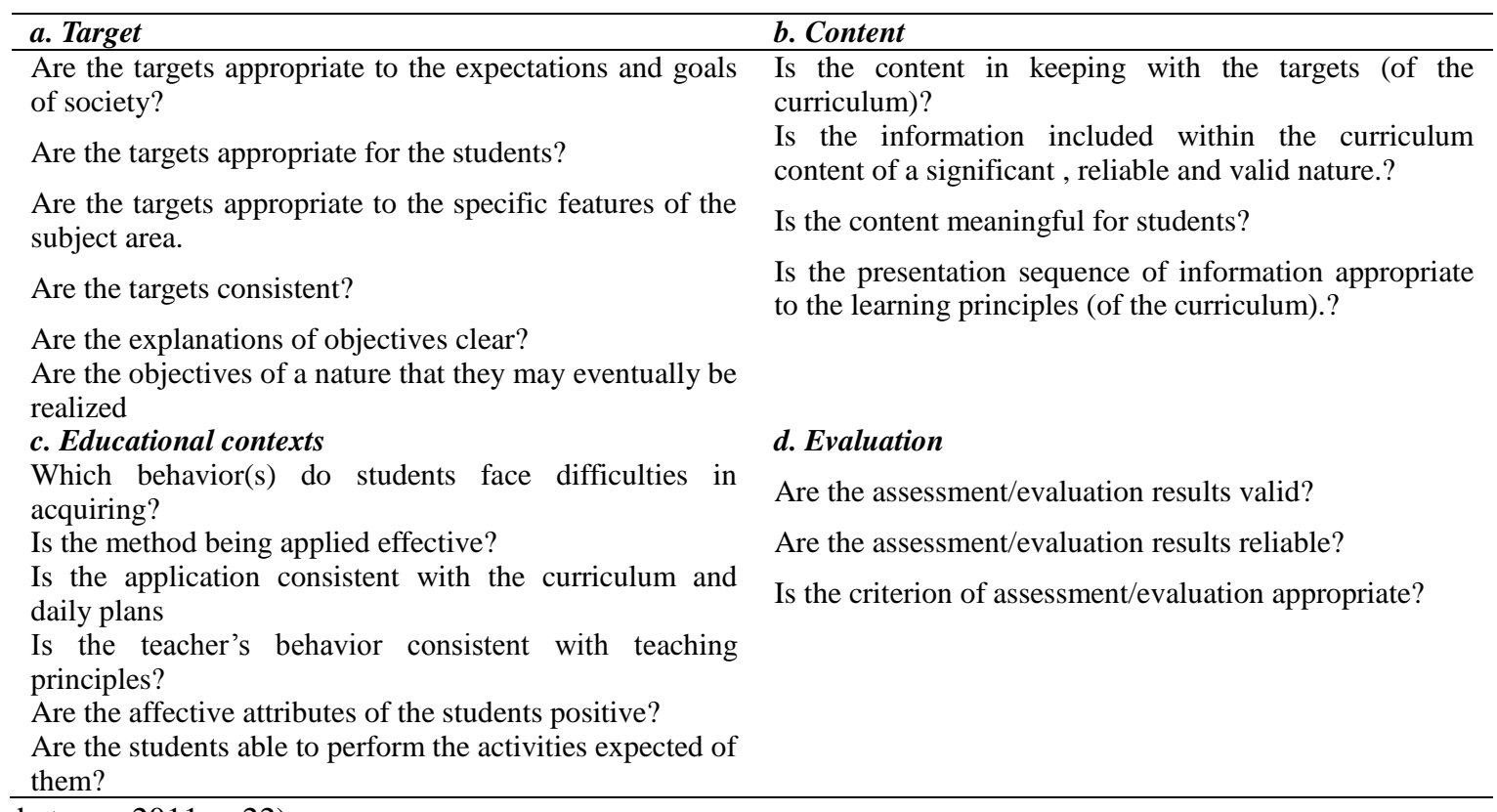

(Kocabatmaz, 2011, p.22).

This study was conducted with the aim of evaluating the effectiveness of high school curricula from the perspective of the opinions of teachers. The principle aim of the research is to evaluate the application of existing high school curricula and to identify problems concerning these programs. Through this research, it was aimed to arrive at an evaluation of high school curricula that has been based on principles of progressive educational philosophy and constructivist teaching theory as held by teachers employed at public high schools.

This study assumes importance in the way that it allows for opportunities for research into whether high-school curricula (re)constituted in accordance with contructivist learning theory are being conducted in conjunction with the basic principles of the theory. The study also attempts to determine whether inadequate or deficient aspects are found within such curricula. The study is also to be considered as important in the way it offers opportunities and unique insights to both curriculum designers and users assigned with implementing such programs as well as academicians wishing to conduct research on the topic of curriculum assessment. Furthermore, this study is anticipated to be of benefit in offering opportunities to observe the current state of school curricula. The researcg may may also suggest what actions need to be taken through an examination of curricula from the perspective of existing educational theory, 
and through the identication of current deficiencies and inadequacies serve to address and correct them. Moreover, the study assumes an important role in the way that it identifies how curricula based on the constructivist approach are perceived from the perspective of teachers. It therefore offers valuable insights into the impact and effectiveness of high school curricula as a whole.

In this context, the research questions were formulated as follows:

1) What are the opinions of high school teachers concerning the objective components of high school curricula?

2) What are the opinions of high school teachers concerning the content components of high school curricula?

3) What are the opinions of high school teachers concerning the learning components of high school curricula?

4) What are the opinions of high school teachers concerning the evaluation components of high school curricula.

\section{Method}

A descriptive survey model was employed for this study. According to Karasar (2005), the descriptive survey model endeavors to reflect a situation as it really 'exists' or is. In this model, an attempt is made to describe the event, individual or object that is to be taken for consideration or examination within its own natural conditions and the state in which it exists (its real-existing condition). The element-based curriculum evaluation approach proposed by Erden was accepted as the method of research to be employed within the context of the curriculum evaluation included in this research. As a program evaluation model, for the purposes of this study, the "element-based curriculum evaluation model" was taken as the basis for the research. By choosing such a model, it was considered that this would allow for a hollistic and comprehensive evaluation taking into consideration all elements of high school curricula.

\subsection{Participants}

The study group for this research consisted of 199 high school teachers employed at public high schools in the city of Istanbul during the 2015-2016 academic year. These teachers selected via simple random sampling. In the simple random sampling process, the probability of every member of the population of a potential study group to be selected is identical. The selection of one member from within the group does not influence the selection of the other members (Şehirlioğlu, 2010). The teachers were employed across different subject disciplines. These subjects were: Mathematics, Geography, Foreign Languages, History, Turkish Revolutionary History and Kemalism, Physics, Biology, Religious and Moral Education, and Turkish Language and Literature and Philosophy-related subjects. The defining characteristics of the 199 teachers who participated in the study are presented below:

Table 2. Defining characteristics of participants

\begin{tabular}{llll}
\hline Tables & Groups $\boldsymbol{f}$ & $\mathbf{\%}$ \\
\hline \multirow{3}{*}{ Gender } & Female & 71 & 35,7 \\
\cline { 2 - 4 } & Male & 128 & 64,3 \\
\cline { 2 - 4 } & Total & 199 & 100,0 \\
\hline
\end{tabular}

\subsection{Data Collection Tools}

In this study, a questionnaire with a five-point likert scale was used. The questionnaire consisted of two sections dedicated to the collection of demographic data and the opinions of teachers regarding high-school curricula. In the section for demographic data, information regarding the gender of the teacher was requested and explanations concerning the aim of the research study and its theme of focus were included. In the second part, teachers were requested to indicate their opinions concerning the objectives, content, educational contexts and evaluation aspects of high school curricula. At the questionnaire-development stage, sources available from existing academic literature on the topic were examined and similar studies were also reviewed. The information deemed appropriate for the purpose of the study was compiled into a 'resource pool' and there was an attempt to questions were then produced in the light of the information obtained. Following this stage, support was elicited from four experts in the fields of curriculum development and teaching theory with particular focus on the subject of constructivism. The initial evaluations that included 26 survey items were then altered and reduced and a draft questionnaire was created consisting of 22 items. In addition, in terms of the extent of the scale and face validity, items in similar scales from different research studies were carefully examined. The items which are in the scales in previous research studies were utilized by critically employing them. At a later point, with view to ensuring the validity of the scope and configuaration of the questionnaire, the opinions of experts in the field were elicited and following an evaluation process, the number of items on the questionnaire were fixed at 19.

The high school curricula were then examined from the perspective of their basic components, general characteristics, their founding principles and the educational philosophy and teaching theory to which attention was focussed., A total of 19 questions were included in the questionnaire that addressed the following aspects: learning objectives, content, 
educational contexts and evaluation.. In the questionnaire, 4 statements were then formulated with respect to the attainment objectives of the curriculum, 5 with regard to the curriculum content, 6 concerning components related to the element of educational contexts and finally 4 related to the element of curriculum evaluation. The questions were organized according to a a five-point likert scale. Independent and non-related subheadings were then created for the fundamental elements of the curriculum for the questionnaire, namely: learning objectives, content, educational contexts and evaluation.

\subsection{The Data Collection Process}

Data were collected via implementation of the questionnaire prepared in advance from teachers employed at public high schools situated in the province of Istanbul. These teachers participated in the study on a voluntary basis between December 2015 and January 2016 Required appointments at the schools that has been chosen as the sample institutions for the study were arranged and the mandatory consent documents were prepared. At the questionnaire-completion stage, explanations were made to the participating teachers (concerning the aims of the research). The data was then transferred to a digital format and all processes were carried out using electronic media.

\subsection{Data Analysis}

The data obtained from the study were then analyzed using SPSS 22.00 software. At the data evaluation stage, the number, percentage, mean average and standard deviation were used as descriptive statistical methods. The Cronbach's alpha was calculated at 0.948 . The confidence interval of the data obtained was calculated at $95 \%$ with a significance level of $5 \%$.

The arithmetical averages when interpretated with intervals of 0.80 (5/4) are expressed as follows: (1.00-1.80 very low, 1.81-2.60 low, 2.61-3.40 medium, 3.41-4.20 high, 4.21-5.00 very high). The data obtained in this study were interpreted according to the level/size of the arithmetical average as follows: very low, low, medium, high and very high.

\section{Data and Interpretations}

The findings were obtained as a result of analysis of the data collected via the questionnaire answered by teachers participating in the study with view to finding a solution to the problem addressed by this research. In this section, explanations and comments were submitted based on the data obtained. The data relating to the opinions of teachers, reflect the frequency, percentage, average and standard deviation values of the opinions indicated on the questionnaire with regard to the evaluation component of the teaching program for high schools and with respect to the 19 statements (EK11) that emerged.

The distribution of the responses submitted by participant teachers in the study with regard to attainment objectives is seen in Table 3 below.

Table 3. Distribution of the teachers' responses regarding learning objectives.

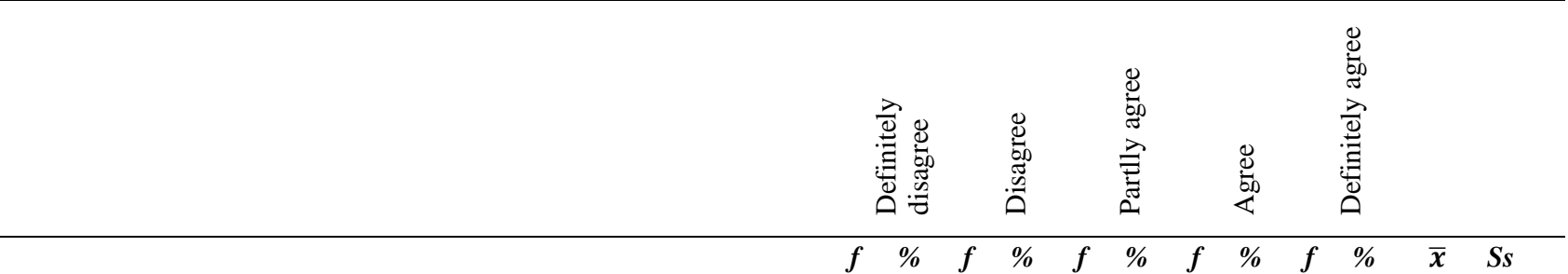

The attainment objectives of the curricula are of a nature as to provide

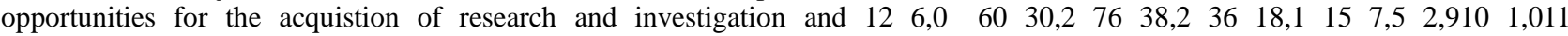
problem solving skills as anticipated in the teaching program.

The attainment objectives indicated in the curricula are of a sufficient quality so as to provide opportunities not merely for the transfer of knowledge to the student, but also for research and observation by the $\begin{array}{llllllllllll}23 & 11,6 & 58 & 29,1 & 66 & 33,2 & 36 & 18,1 & 16 & 8,0 & 2,819 & 1,109\end{array}$ student.

The attainment objectives indicated in the curricula are of a sufficient quality so as to provide opportunities for critical, creative and analytical $16 \quad 8,0 \quad 92 \quad 46,2 \quad 47 \quad 23,6 \quad 28 \quad 14,1 \quad 16 \quad 8,0 \quad 2,678 \quad 1,072$ thinking on the part of the student.

There is recourse to different methods and techniques to reach the different objectives of the teaching process.

On examination of the answers submitted by the participant teachers with regard to attainment objectives, the average level of teachers in agreement with the statement "The learning objectives of the curricula are of a nature as to provide opportunities for research and investigation and problem solving skills as anticipated in the teaching program" was determined at $(2,910 \pm 1,011)$. The average level of teachers in agreement with the statement "The learning objectives 
indicated in the curricula are of a sufficient quality so as to provide opportunities not merely for the transfer of knowledge to the student, but also for research and observation by the student" was established at $(2,819 \pm 1,109)$.

The average level of teachers in agreement with the statement "The learning objectives indicated in the curricula are of a sufficient quality so as to provide opportunities for critical, creative and analytical thinking on the part of the student" was established at $(2,678 \pm 1,072)$. The average level of teachers that agreed with the statement "There is recourse to different methods and techniques to reach the different objectives of the teaching process" was determined at $(3,095 \pm$ $0,808)$.

The distribution of the answers submitted by teachers regarding content are seen in Table 4 .

Table 4 . The distribution of the responses submitted by teachers regarding content.

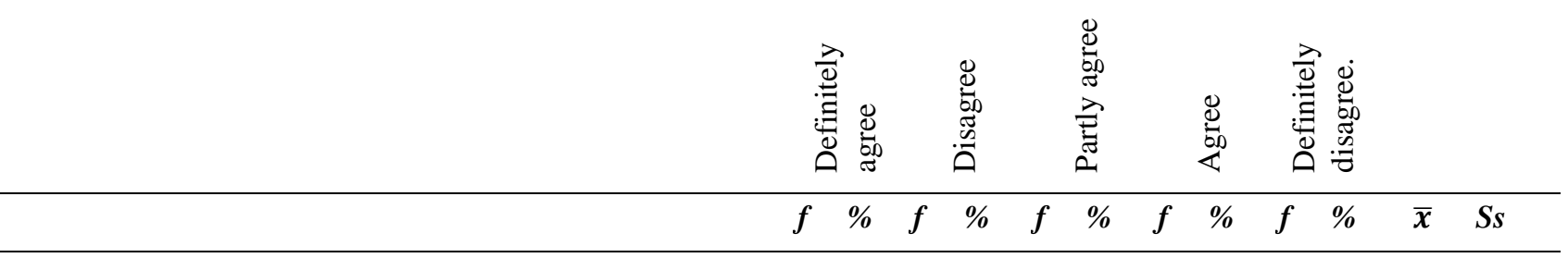

The topics set out in the curriculum (theme, content etc) provide opportunity for high level attainment outcomes moving beyond mere memorization to aspects such as enhanced comprehension, $\begin{array}{llllllllllll}20 & 10,1 & 82 & 41,2 & 47 & 23,6 & 39 & 19,6 & 11 & 5,5 & 2,693 & 1,069\end{array}$ analysis, synthesis and evaluation.

The topics set out in the curriculum (theme, content etc) provide

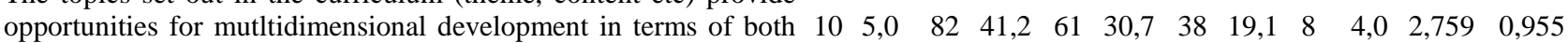
cognitive as well as affective and kinetic domains.

The topics set out in the curriculum (theme, content etc) are of a

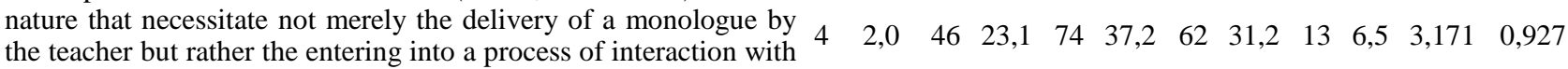
the student(s).

The topics set out in the curriculum (theme, content etc) allow for $8 \quad 4,0 \quad \begin{array}{llllllllll}27,1 & 80 & 40,2 & 50 & 25,1 & 7 & 3,5 & 2,970 & 0,910\end{array}$ the opportunity to reach attainment outcomes at various levels.

The topics set out in the curriculum (theme, content etc) incorporate knowledge and skills that are needed in real life.

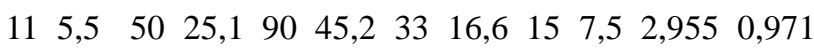

On examination of the answers submitted by the participant teachers with regard to the attainment objectives;

The average level of teachers that agreed with the statement "the topics set out in the curriculum (theme, content etc) provide opportunity for high level attainment outcomes moving beyond mere memorization to aspects such as enhanced comprehension, analysis, synthesis and evaluation" was established at $(2,693 \pm 1,069)$.

The average level of teachers that agreed with the statement "the topics set out in the curriculum (theme, content etc) provide opportunities for mutltidimensional development in terms of both cognitive as well as the affective and kinetic domains" was calculated at $(2,759 \pm 0,955)$. The average level of teachers that agreed with the statement "the topics set out in the curriculum (theme, content etc) are of a nature that necessitate not merely the delivery of a monologue by the teacher but rather the entering into a process of interaction with the student(s)" was established at (3,171 $\pm 0,927)$.

The average level of teachers that agreed with the statement "the topics set out in the curriculum (theme, content etc) allow for the opportunity to reach attainment outcomes at various levels" was calculated at (2,970 $\pm 0,910)$ r. The average level of teachers that agreed with the statement "the topics determined in the curriculum (theme, content etc) incorporate knowledge and skills that are needed in real life” was established at $(2,970 \pm 0,910)$.

The distribution of responses issued by teachers with regard to educational contexts is seen in Table 5. 
Table 5. Distribution of responses to statements 1ssued by teachers regarding educational contexts.

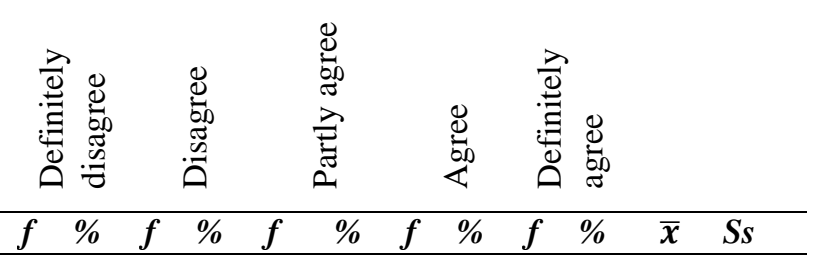

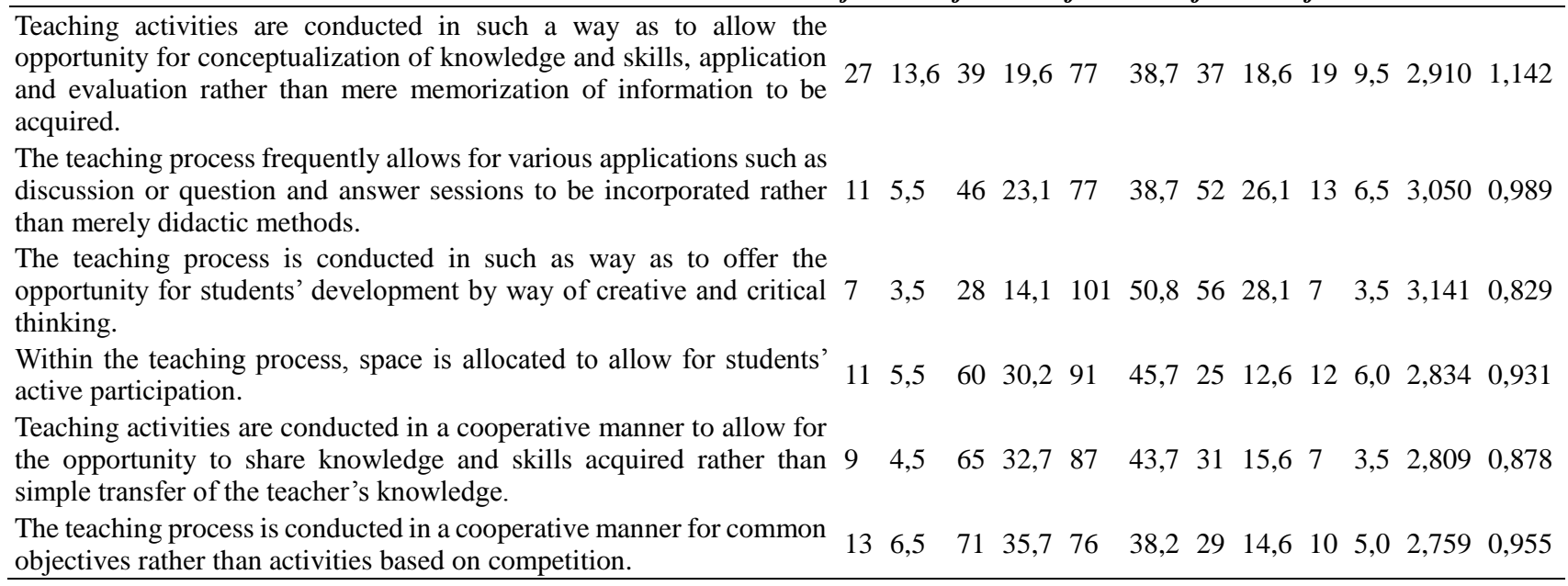

On examination of the responses submitted by the participant teachers with regard to the attainment objectives;

The average level of teachers that agreed with the statement "teaching activities are conducted in such a way as to allow the opportunity for conceptualization of knowledge and skills, application and evaluation rather than mere memorization of information to be acquired" was established at $(2,910 \pm 1,142)$ The average level of teachers that agreed with the statement that "the teaching process frequently allows for various applications such as discussion or question and answer sessions to be incorporated rather than simply didactic methods" was calculated at (3,050 \pm 0,989).

"The average level of teachers that agreed with the statement "The teaching process is conducted in such as way as to offer the opportunity for students" development by way of creative and critical thinking" was established at $(3,141 \pm$ $0,829)$ The average level of teachers that agreed with the statement "Within the teaching process, space is allocated to allow for students' active participation" was calculated at $(2,834 \pm 0,931)$.

"The average level of teachers that agreed with the statement "Teaching activities are conducted in a cooperative manner to allow for the opportunity to share knowledge and skills acquired rather than simple transfer of the teacher's knowledge" was established at $(2,809 \pm 0,878)$. The level of teachers that agreed with the statement "the Teaching process is conducted in a cooperative manner to reach common objectives rather than activities based on competition" was calculated at $(2,759 \pm 0,955)$. 
The distribution of teachers participating in the study with respect to the statements concerning evaluation is seen in Table 6 .

Table 6. Distribution of the responses submitted by teachers regarding evaluation.

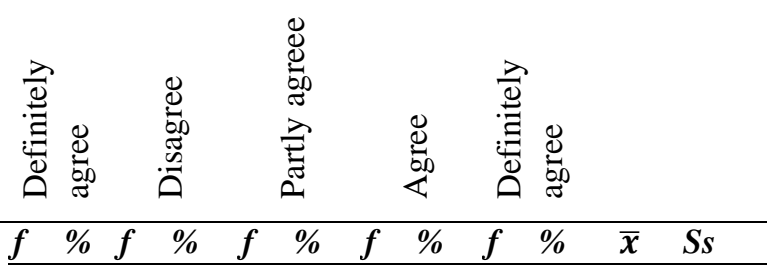

Within the assessment and evaluation process there is recourse to methods of evaluation other than written tests.

$\begin{array}{lllllllllllll}13 & 6,5 & 42 & 21,1 & 80 & 40,2 & 59 & 29,6 & 5 & 2,5 & 3,005 & 0,935\end{array}$

The tools of assessment employed within the assessment and evaluation

process are of a nature that attainment outcomes may be successfully $5 \quad 2,5 \quad 39 \quad 19,6 \quad 82 \quad 41,2 \quad 62 \quad 31,2 \quad 11 \quad 5,5 \quad 3,176 \quad 0,896$ evaluated.

Within the assessment and evaluation process, students' development in

the affective and kinetic domains may be assessed in addition to mere $13 \quad 6,5 \quad 46 \quad 23,1 \quad 91 \quad 45,7 \quad 39 \quad \begin{array}{llllll}19,6 & 10 & 5,0 & 2,935 & 0,943\end{array}$ cognitive development.

The assessment and evaluation process is conducted in such a way as to

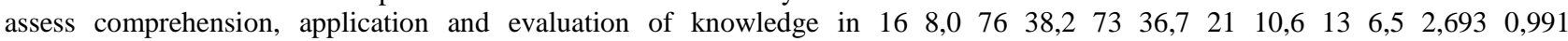
addition to mere retention of information.

\section{On examination of the answers submitted by the participant teachers with regard to the evaluation objectives;}

The average level of teachers that agreed with the statement "within the assessment and evaluation process there is recourse to methods of evaluation other than written tests" was established at $(3,005 \pm 0,935)$. The average level of teachers that agreed with the statement "The tools of assessment employed within the assessment and evaluation process are of a nature that attainment outcomes may be successfully evaluated" was calculated at $(3,176 \pm 0,896)$.

The average level of teachers that agreed with the statement "Within the assessment and evaluation process, students development in the affective and kinetic domains may be assessed in addition to mere cognitive development" was established at $(2,935 \pm 0,943)$ The average level of teachers that agreed with the statement "The assessment and evaluation process is conducted in such a way as to assess comprehension, application and evaluation of knowledge rather than mere retention of information" was calculated at $(2,693 \pm 0,991)$.

Table 7. The opinions of teachers regarding components of the high school curriculum in percentage form.

\begin{tabular}{llllll}
\hline Program components & $\begin{array}{l}\text { Definitely } \\
\text { disagree }\end{array}$ & Disagree & Partly agree $\%$ & Agree $\%$ & Definitely agree $\%$ \\
\hline Attainment Objectives & 6,65 & 31,65 & 36,05 & 18,75 & 6,9 \\
\hline Content & 5,33 & 31,55 & 35,4 & 22,32 & 5,5 \\
\hline Educational contexts & 6,52 & 26 & 42,63 & 19,26 & 5,66 \\
\hline Evaluation & 5,9 & 25,5 & 40,95 & 22,75 & 4,9 \\
\hline General average\% & 6,1 & 28,69 & 38,75 & 20,76 & 5,7 \\
\hline
\end{tabular}

When the opinions of teachers with respect to the 19 items included in the questionnaire regarding components of the High School curriculum are considered in percentage terms, it can be seen that the largest percentage of responses fall into the category of "partly agree". When the general averages with respect to elements of the curriculum are taken into consideration, the total of answers submitted and included under the "agree" and "definitely agree" categories are found to be $26.46 \%$ In contrast, the total for the "disagree" and "definitely disagree" categories when considered as a general average are seen to be $34.79 \%$.

\section{Discussion and Conclusion}

According to the findings obtained from the study, it was established that teachers agreed with all components of the high school curriculum at an average level. According to these results, the teachers' evaluations with respect to all elements contained within the curriculum currently in practice are at a medium level. When the averages, frequencies and percentages of the tables that express the evaluations of high school teachers with regard to elements of the high school curricula(table 2, table 3, table 4) are taken into consideration, it may be stated that these indicate a compatibility with the academic literature published on the same subject. (Arslan \& Demirel, 2007; Dinç \& Doğan, 2010; Doğanay \& Sar1, 2008) In a similar manner, it was observed in a study conducted by Bayrak and Erden (2007), that 51\% of 
participant teachers expressed positive opinions with regard to the elements concerning the educational contexts within the program. In a study carried out by Kösterelioğlu and Özen (2014), it emerged that the opinions of class teachers responsible for teaching fourth grade classes with regard to the attainment objectives, content and evaluation aspects of the social science curriculum were at a "medium" level. However, their opinions with respect to the teaching process did not correspond to those that emerged from this study and were found to be at a "high" level. (Özen, 2014).

Furthermore, when the percentages of the teachers' responses to the 19 items featured in the questionnaire with respect to the elements of the high school teaching program, the following results emerged: $6.1 \%$ 'disagree', $28.69 \%$ 'partially disagree'(?), 38.75\% 'agree' (?), 20.76\% 'partly agree' and 5.7\% 'definitely agree'. However, while the total for the responses of 'agree' and 'definitely agree' total $26.46 \%$, the largest agreement with a general average was $34.79 \%$ and there was a total of $34.79 \%$ for the 'disagree' or 'definitely disagree' categories. The largest agreement was actually for that of the option "partially agree'. These results indicate that teaching programs/curricula based on the constructivist approach have not been completely adopted/embraced by those teachers who remain responsible for their application and from this perspective, by extension, it is therefore difficult for such plans to reach their objectives. In particular, the fact that the combined general percentage for the "disagree" and "definitely disagree" is higher than that of the combined general percentage for "definitely agree" and "agree" offers food for thought. Program evaluation involves a focus on whether a given program has reached its desired results or not. (Ornstein \& Hunkins, 2009). Results that emerge for a given curriculum in which the expected final target is at a "high" or "very high" rather than a "medium" level indicate that there are problems with all elements of the existing curricula and furthermore that teachers who are in the position of delivering the program are not aware of the elements of the curricula and (it follows) that curricula do not have the efficiency that is expected of them. The results obtained from this study are seen to contradict the results of the study conducted by Alkan and Arslan (2014). In that study, the researchers reached the conclusion that the opinions of teachers with regard to the curricula were overwhelmingly positive, with teachers submitting 31 positive and 11 negative responses to the 42 items contained in their questionnaire.

In this study, on examination of the responses submitted by teachers, the aforementioned participant teachers were seen to agree with the statments presented with regard to the attainment objectives of high school teaching programs at a level of $(2,875 \pm 1)$. Ar1 (2014) in his study that focused on the English curriculum applied in sixth grades, came to the conclusion that participant teachers believed that the targets stipulated in the (existing) curricula could not be reached. When the findings of a study conducted by Alkan and Arslan (2014) concerning participants' perceptions of the target elements of the curriculum, and when findings regarding the target elements for English lessons are examined, teachers from the perspective of attainment objectives submitted positive responses concerning 7 of the 8 program elements. Such results contradict the results obtained in this study. In this study, the evaluation may be reached that the teachers did not show themselves as feeling positive to a high degree concerning the quality of the attainment In this context, in curriculum development studies, actions should be taken to bring about reforms to curricula paying more attention to elements such as their appropriacy to the realities faced by students, their applicability to real life and comprehensibility on the part of the teachers.

In this study, it may be seen on examination of the responses submitted by teachers that participant teachers agreed with the statements concening the content elements of high school curricula at an average level of $(2,875 \pm 1) \mathrm{Kandemir}$ (2016) in his study reached the conclusion that teachers experienced indecisiveness concerning the content elements of the curriculum. While they expressed positive opinions regarding certain elements, they also expressed negative views regarding others, and that they had experienced practical difficulties concerning the (applicaion of) content elements of the program. Ekşioğlu and Taşpınar (2014), in their study, reached the conclusion that teachers expressed the view that the teaching programs currently in practice only partially incorporated the qualities that were expected from the perspective of content. The results of the study conducted by Bayrak and Erden (2007) however contradicted the findings of the previously-mentioned. study. In this study, the researchers reached the conclusion that teachers were in agreement that the content of the program was consistent with the intentions expressed within the attainment objectives, and that the introduction of topics was conducted in a hierarchial fashion moving from the simple to the complex and that this content guided the student towards comprehension rather than mere memorization.

In this study, it is observed on consideration of the responses submitted by teachers, that the aforementioned participant teachers agreed with the statements concerning the educational contexts of high school curricula at an average level of $(2,917 \pm 0,954)$ In a study conducted by Ekşioğlu and Taşpınar (2014) similar results were seen to emerge. In this particular study, it was observed that the elements of a modular teaching program relating to educational contexts partially conveyed the expected characteristics as expressed in the program. A similar result was reached in a study conducted by Butakın and Özgen (2007) In that study, the conclusion was reached that teachers held opinions at a 'medium' level concerning the application of teaching programs. These results indicate that those teaching programs based on the constructivist approach were not applied in the desired fashion, that student-centred learning philosophies 
had not been adopted at the required level and that adequate space/scope was not allocated within the application of the program for teaching activities that incorporated learning through doing and experiencing.

In this study, it may be seen, on consideration of the answers submitted by teachers, that the aforementioned participant teachers agreed with the statements regarding the evaluation elements of high school teaching programs at an average level of $(2,952 \pm 0,941)$. Kösterlioğlu and Özen (2014) reached the conclusion that the opinions of teachers with regard to the evaluation elements contained within the program for social science lessons in fifth grades were $(\mathrm{x}=3.36)$ for fourth and $(\mathrm{x}=3.34)$ for fifth grades. Adigüzel and Berk (2009) reached similar conclusions in their study addressing teachers' opinions with regard to the evaluation element(s) of curricula.

According to the results of this study high school teachers' views have been examined and they have been found to be in agreement with all elements of the high school program at a medium level. It is therefore suggested that the teaching principles, constructivist teaching theory and the (basic) attainment objectives deemed essential by the National Ministry of Education need to be reviewed. In this respect, opportunities need to be created so as to present teachers with the opportunity to become sufficiently acquainted with existing curricula and to understand them more effectively. A great need has been perceived for the constructive criticism (of exisiting programs) so as to evaluate the appropriacy of targets with concern to the characteristics of the students concerned, the extent to which real-life knowledge and skills are incorporated, the degree of participation of students in the learning process. There is also a need at the evaluation stage for a process-based, authentic means of evaluation. Moreover, opportunities should be presented so as to raise teachers' awareness of elements of the curricula and their levels of consciousness with regard to educational theory. In particular, guidance should be offered to teachers concerning the use of different methods and techniques that may offer an opportunity to ensure greater student participation in the educational process and with regard to the application of alternative techniques within the evaluation process.

\section{References}

Adiguzel, O. C., \& Berk, S. (2009). New Quests in Vocational and Technical Secondary Education: Evaluation of Competence-Based Modular System, Centenary University Faculty of Education Journal, 4(1), 220-236.

Akdeniz, N. (2008). Difficulties of teachers in their Act Compliance Process Innovation Brought new program. Unpublished Master Thesis, Konya: Selcuk University Institute of Social Sciences.

Alkan, M. F., \& Arslan, M. (2014). Evaluation of the $2^{\text {nd }}$, Grade English Language Curriculum. International Curriculum and Instruction Studies, 4(7).

Ari, A. (2014). Teacher Opinions about Evaluation of 6th Grade English Lesson Curriculum in Primary Schools. Journal of Theoretical Educational Science, 7(2), 172-194. http://dx.doi.org/10.5578/keg.6646

Aslan, D., \& Aydin, H. (2015). Evaluation of the Teaching Processes at Science High Schools Based on a Constructivist Approach. A Scale Development Study. Oxidation Communications, 38(1A), 472-491.

Aydin, H. (2012). Multicultural Education Curriculum Development in Turkey. Mediterranean Journal of Social Sciences, 3(3), 277-286.

Aydin, H. (2013). A Literature-based Approaches on Multicultural Education. The Anthropologist, 16(1-2), 31-44.

Bayrak, B., \& Erden, M. (2007). The Evaluation of Science Curriculum, Kastamonu Education Journal, 15(1), 137-154.

Butakin, V., \& Ozgen, K., (2007). An Evaluation of the Effectiveness of the New Mathematics Curriculum, Which Applied Primary School in Practice, Diyarbakir Example. D. University. Ziya Gokalp Education Faculty Journal, 8, 82-94.

Demirel, O. (2013) Kuramdan Uygulamaya Eğitimde Program Geliştirme, Ankara: PegemA Yayınc1lık.

Dinc, E., \& Dogan, Y. (2010). Middle School Social Studies Curriculum and Teachers' Opinions about Adoption, Journal of Social Studies Education Research, 1(1), 17-49.

Doganay, A., \& Sari, M. (2008). The New Social Studies Curriculum from the Teachers' Point of View: A Study in the Adana Province of Turkey. Elementary Education Online, 7(2), 468-484.

Dilmac, Y. (2008). New elementary school social studies teachers' views on the applicability of the curriculum (Istanbul European Side Case). Unpublished Master Thesis, Yeditepe University Institute of Social Sciences, İstanbul.

Eksioglu, S., \& Taspinar, M. (2014). Evaluation of Modular Education Program İmplementation İn Vocational and Technical High Schools. International Journal of Human Sciences, 11(2), 1203-1223.

http://dx.doi.org/10.14687/ijhs.v11i2.3095 
Erden, M. (1995). Teacher Certification of Teacher Candidates Attitudes towards the Course. Hacettepe University Journal of Education, 11, 99-104.

Erden, M. (1998). Eğitimde Program Değerlendirme. Ankara: Anı Yayıncılık.

Erturk, S. (1993). Eğitimde Program Geliştirme. Ankara: Meteksan.

Gomleksiz, M. N. (2005). New Primary School Curriculum in practice Evaluation of the Effectiveness. Theory \& Practice of Education Journal of Science, 5 (2), p. 339-384.

Hakan, A., Saglam, M., Sever, D., \& Vural, L. (2011). Evaluation of Anadolu University Social Sciences İnstitution's Curriculum, International Education in Curriculum and Instruction Studies Journal, 1(1).

Karatas, K., \& Oral, B. (2015). Teachers' Perceptions on Culturally Responsiveness in Education. Journal of Ethnic and Cultural Studies, 2(2), 47-57.

Karasar, N. (2005). Bilimsel Araştırma Yöntemi (15. Basım). Ankara: Nobel Yayınları.

Kandemir, A. (2016). An Evaluation of 2nd Grade English Curriculum within a Participant Oriented Program Evaluation Approach, Unpublished Master Thesis, Pamukkale University, Institute of Education Sciences.

Kaya, Y. (2015). The Opinions of Primary School, Turkish Language and Social Science Teachers regarding Education in the Mother Tongue (Kurdish). Journal of Ethnic and Cultural Studies, 2(2), 33-46.

Kocabatmaz, H. (2011). The evaluation of the technology and design curriculum, unpublished dissertation, Ankara University Institute of Educational Sciences. (s.22).

Koufman, R., \& Thomas, S. (1980). Evaluation without Fear. New York: New Viewpoints.

Kosterelioglu, I., \& Ozen, R. (2014). Fourth and Fifth Grade Social Studies Elements of the Curriculum Evaluation of the Bolu province Example, Amasya University Faculty of Education Journal, 3(2), 286-316.

MEGEP. (2006). Öğretim Programları Ve Moduller Öğretim Uygulama Kılavuzu, http://www.megep.meb.gov.tr/dokumanlar/diger/ogretmen_kitap.pdf (reached on 18 February).

Sönmez, V. (2015). Program Geliştirmede Öğretmen El Kitabı (18. Basım). Ankara: Anı Yayınları.

Ornstein, A. C., \& Hunkins, F. P. (2009). Curriculum foundations, principles, and issues (5th ed.). Boston, MA: Pearson. Tyler, R. W. (2013). Basic Principles of Curriculum and İnstruction. USA: The University of Chicago Press.

Varis, F. (1976). Training Program Development. Theory and Techniques. Ankara: AU Faculty of Education, Publication, 53.

Yuksel, I., \& Saglam, M. (2012). Eğitimde Program Değerlendirme. Ankara: Pegem Akademi.

Yurtseven, N., \& Altun, S. (2015). Intercultural Sensitivity in Today's Global Classes: Teacher Candidates' Perceptions. Journal of Ethnic and Cultural Studies, 2(1), 49-54.

\section{Appendix 1}

\section{Questionnaire for the Evaluation of High School Curricula using the Element-Based Curriculum Evaluation Model}

\section{Dear Participants}

This study aims to conduct an evaluation of the components included in high school curricula, namely: attainment objectives, content, educational contexts and evaluation from the perspective of teachers. It is hoped that the findings obtained will serve as a starting point to create opportunities that will allow for more effective and productive processes of curriculum planning and development.

With this in mind, we kindly request you to spare your valuable time and to share your opinions on the issues concerned by indicating the options that are most appropriate for you and so help us reach the goal indictaed above. Please submit your responses to the statements indicated below with complete honesty and sincerity. We express our respect and thanks in advance.

Dr. Dolgun Aslan

Rafet Günay 


\section{Gender: Female ( ) Male ( )}

Element-based curriculum evaluation items concerning teachers' opinions

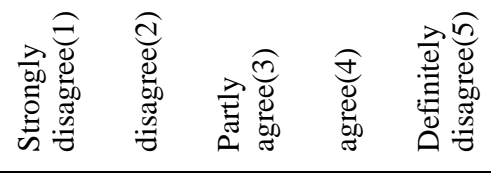

A. Statements concerning attainment objectives

1. The attainment objectives set out in the curriculum are of a sufficient nature as to provide opportunities for the acquistion of research and investigation and problem solving skills

2. The attainment objectives indicated in the teaching programs are of a quality so as to provide opportunities not merely for the transfer of knowledge to the student, but also for research and observation by the student

3. The attainment objectives indicated in the teaching programs are of a quality so as to provide opportunities for critical, creative and analytical thinking on the part of the student.

4. There is recourse to different methods and techniques to reach the different objectives of the teaching process.

B. Statements concerning Content Elements

5. The topics set out in the curriculum (theme, content etc) provide opportunity for high level attainment outcomes moving beyond mere memorization to aspects such as enhanced comprehension, analysis, synthesis and evaluation

6. The topics determined in the curriculum (theme, content etc) provide opportunities for mutltidimensional development in terms of both cognitive as well as the affective and kinesthetic domains.

7. The topics set out in the curriculum (theme, content etc) are of a nature that necessitate not merely the delivery of a monologue by the teacher but rather the entering into a process of interaction with the student(s)

8. The topics set out in the curriculum (theme, content etc) allow for the opportunity to reach attainment outcomes at various levels.

9. The topics set out in the curriculum (theme, content etc) incorporate knowledge and skills that are needed in real life.

C. Statements Concerning Educational Contexts

10. Teaching activities are conducted in such a way as to allow the opportunity for conceptualization of knowledge and skills, application and evaluation rather than mere memorization of information to be acquired.

11. The teaching process frequently allows for various applications such as discussion or question and answer sessions to be incorporated rather than simply didactic methods.

12. The teaching process is conducted in such as way as to offer the opportunity for students' development by way of creative and critical thinking.

13. Within the teaching process, space is allocated to allow for students' active participation.

14. Teaching activities are conducted in a cooperative manner to allow for the opportunity to share knowledge and skills acquired rather than simple transfer of the teacher's knowledge.

15. The teaching process is conducted in a cooperative manner in pursuit of common objectives rather than activities based on competition.

D. Statements concerning Evaluation Elements

16. Within the assessment and evaluation process there is recourse to methods of evaluation other than written tests

17. The tools of assessment employed within the assessment and evaluation process are of a nature that attainment outcomes may be successfully evaluated.

18. Within the assessment and evaluation process, students' development in the affective and kinetic domains may be assessed in addition to mere cognitive development.

19. The assessment and evaluation process is conducted in such a way as to assess comprehension, application and evaluation of knowledge rather than mere retention of information.

This work is licensed under a Creative Commons Attribution 3.0 License. 